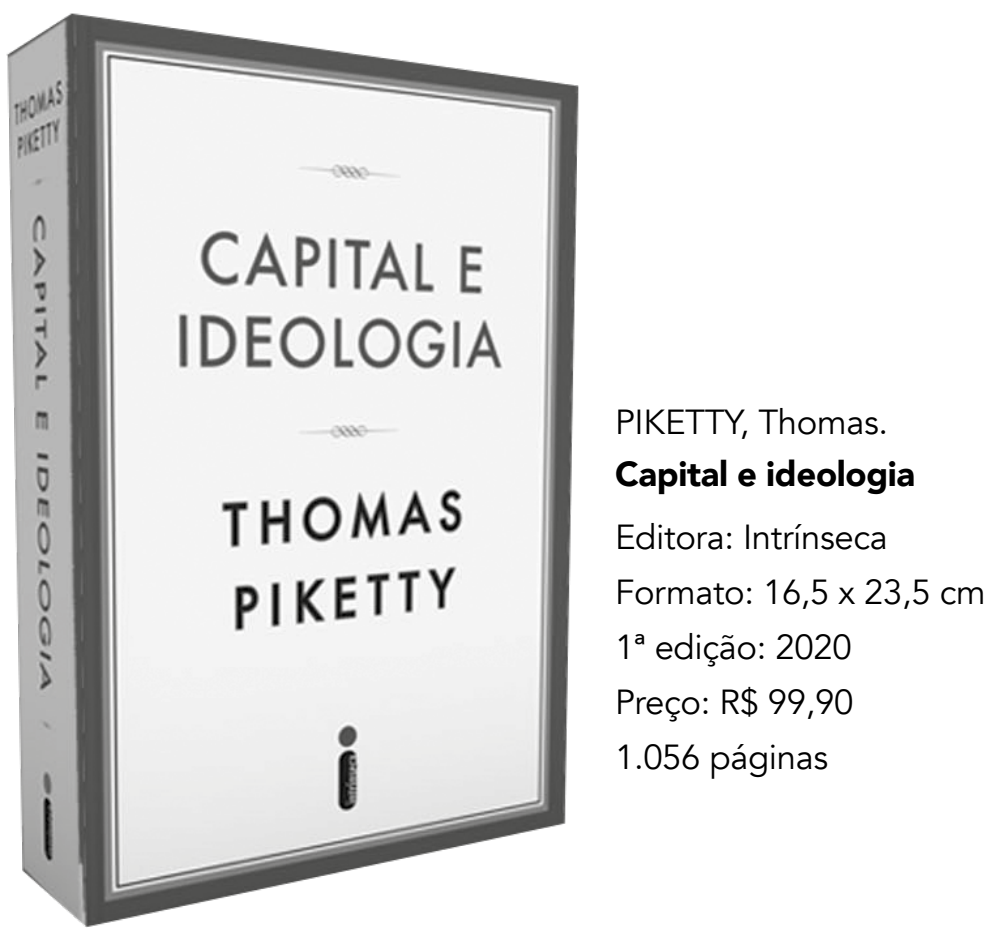

\title{
Um libelo contra a ideologia "proprietarista"
} A libel against proprietors' ideology

\section{Marcelo pereila Fernandes*}

Thomas Piketty ficou célebre com o livro O capital no século XXI, publicado em 2013 na França. Capital e ideologia, segundo o próprio autor, é um prolongamento daquele primeiro trabalho. No livro, Piketty, em mais de mil páginas e com uma fonte ampla de dados estatísticos, discute a questão da desigualdade socioeconômica. Desde os anos I980, e particularmente embaladas pelo fim da URSS em I99I, as desigualdades crescem na maioria das regiões do mundo, tornando-se na visão do autor um desafio tão importante quanto o aquecimento global. Como veremos, trata-se de um livro indispensável para quem quer entender como evoluiu a desigualdade desde o feudalismo até os dias atuais. Logo no primeiro parágrafo da introdução, podemos ler aquilo que já é conhecido nos círculos marxistas: “Toda sociedade humana precisa justificar suas desigualdades: tem de encontrar motivos para 
sua existência, ou o edifício político e social como um todo corre o risco de desabar." (p. II) Porém, em confronto com o materialismo histórico, segundo Piketty, existiria "uma autêntica autonomia da esfera das ideias, isto é, da esfera ideológico-política" (p. I7). Ou seja, independentemente do desenvolvimento das forças produtivas haveria sempre diversos regimes ideológicos, políticos e "desigualitários" possíveis. A ideologia está no centro de sua análise.

Além da introdução e da conclusão, o livro se divide em quatro partes, com I7 capítulos ao todo. Nas duas primeiras dessas quatro partes, Piketty busca observar a história dos regimes "desigualitários" por uma perspectiva histórica. Na primeira, intitulada "Os regimes desigualitários na história", Piketty examina o caso das sociedades europeias e sua transformação em sociedades de proprietários. As chamadas "sociedades ternárias" representariam a categoria mais antiga de regime "desigualitário", encontrada em todas as partes do mundo, ainda que com variações consideráveis. $\mathrm{Na}$ forma simples, lembra Piketty, elas seriam compostas por três grupos sociais diferenciados, cada qual defendendo em primeiro lugar seus interesses: clero, nobreza e terceiro estado. O clero é a classe intelectual e religiosa; a nobreza é a classe guerreira e militar, responsável pela proteção e estabilidade da sociedade. E o terceiro estado é composto pela classe trabalhadora, responsável pelas condições materiais do conjunto da sociedade. Segundo Piketty, a importância de estudar as sociedades ternárias vai além de seu interesse histórico: a questão é que as estruturas das antigas sociedades ternárias não seriam uma realidade tão radicalmente distante das sociedades modernas, ao contrário daquilo em que geralmente se acredita. De fato, o ponto importante seria que os regimes políticos que sucederam às sociedades ternárias procuraram renegá-las, como forma de justificar outros sistemas de desigualdades e dominação não necessariamente mais brandos com os grupos dominados.

Assim, a Revolução Francesa, de I789, poderia ser entendida como uma experiência de transformação rápida de uma antiga sociedade ternária. Porém, durante a revolução seriam definidos os poderes soberanos, não uma forma mais justa de distribuição das propriedades, lembra Piketty. Decerto, havia uma visão excessivamente otimista, que a história demonstrou ser equivocada, acerca dos efeitos da abolição dos privilégios de acesso às diferentes profissões, de direito à propriedade e de comércio sobre a redução das desigualdades. A Declaração de Independência dos Estados Unidos, de I776, dizia que todos os homens são dotados de direitos inalienáveis, como a liberdade e a vida. Porém, o seu redator, Thomas Jefferson, era dono de cerca de 200 escravos na Virgínia e assim permaneceu. Propriedades adquiridas no passado não deveriam ser questionadas ou mesmo tributadas em nome de uma concepção de justiça social que poderia levar a sociedade ao caos, brandia a ideologia "proprietarista". Havia uma verdadeira sacralização da propriedade privada, o que criava uma barreira para mudanças distributivas, mesmo que superficiais. Assim, a concentração da propriedade privada na França não parou de crescer do século XIX até o começo da Primeira Guerra, lembra o autor. E quando o imposto progressivo foi adotado na 
França, em I4 de junho de I9I4, era para financiar a guerra contra a Alemanha, e não para financiar serviços públicos.

Ainda na primeira parte, Piketty lembra o papel dos movimentos comunistas, socialistas, social-democratas e trabalhistas, que reivindicavam a construção de um sistema tributário mais justo, após a Primeira Guerra.

$\mathrm{Na}$ segunda parte do livro, Piketty trata das sociedades escravocratas e coloniais. As primeiras constituíam a forma mais extrema de desigualdade. Existiam múltiplas formas de escravidão e trabalho forçado, lembra o autor. Na escravidão os escravos praticamente não tinham direitos. Eram tratados como um bem mobiliário. No caso da servidão, os servos também não tinham direito à mobilidade, porém, ao contrário dos escravos, mantiveram identidade pessoal, podendo até possuir bens e propriedades, ainda que com a autorização do senhor.

Em algumas sociedades o número de escravos alcançaria a proporção de $80 \%$ ou $90 \%$ da população, como no caso do Haiti. A abolição da escravidão no Haiti, resultado de uma revolta dos escravos, é a primeira da Era Moderna. Porém, o exemplo haitiano também seria emblemático por conta da dívida pública gigantesca advinda desse episódio, e "que contribuiu muito para minar o desenvolvimento do Haiti nos dois séculos seguintes" (p. 207). A independência do Haiti foi declarada em I804, mas somente foi reconhecida pela França em I825, após o governo haitiano celebrar um compromisso de pagar à França uma dívida de 150 milhões de francos-ouro como indenização aos proprietários de escravos. Segundo Piketty, tal quantia equivaleria a $2 \%$ da renda nacional francesa da época, o que daria algo equivalente a 40 bilhões de euros como mesma proporção da renda nacional de 2018 , e algo em torno de $300 \%$ da renda nacional do Haiti em I825. Nas décadas seguintes, só com juros, os haitianos desembolsariam cerca de $15 \%$ de sua produção. A dívida de I825 só foi oficialmente quitada em 1950. De fato, o caso haitiano demonstra as ambiguidades da Revolução Francesa que Piketty tentou mostrar na primeira parte da obra. Além de analisar o caso da escravidão nos Estados Unidos e da servidão na Rússia, Piketty se ocupa do Brasil, infelizmente em poucas páginas. De todo modo, é fácil perceber as contribuições nefastas do colonialismo e da escravidão para a desigualdade estrutural dessas sociedades, conforme o autor buscou demonstrar.

A África do Sul, um dos exemplos mais perversos de colonização, após o fim do apartheid viu aumentarem as disparidades de renda entre os $10 \%$ mais ricos e o restante da sociedade, mesmo com o estabelecimento da igualdade formal de direitos. Piketty observa que isso aconteceu em parte porque nunca foi implementada uma verdadeira política redistributiva no país. E não é exatamente surpreendente que, quando o Congresso Nacional Africano (CNA), partido surgido da luta antiapartheid, levantou a ideia de uma reforma agrária, "o presidente dos Estados Unidos, Donald Trump, tenha se apressado em manifestar sua mais forte defesa aos fazendeiros brancos e às suas propriedades fundiárias e ordenado à sua equipe que acompanhasse o caso muito de perto" (p. 273). 


\section{Piketty adverte que a partir} de 1980, sob a influência estadunidense e europeia, a liberalização dos fluxos de capitais e a abertura comercial seriam realizadas em escala mundial, sem qualquer objetivo fiscal e social. Estávamos entrando na era em que o Estado-nação passava a ser cada vez mais questionado pela "revolução conservadora" anglo-saxã financiada por lobbies financeiros

Vale a pena atentar para o caso singular da Índia, que tinha uma ordem quaternária. No topo da hierarquia estavam os brâmanes, que cumpriam as funções de sacerdotes, sábios e letrados. Piketty observa que os colonos britânicos contavam com o apoio dos brâmanes para administrar o país, mas, ao mesmo tempo, os colonos denunciavam a tirania dos brâmanes sobre a Índia para assim justificar sua missão civilizadora. Depois da independência, em 1947, a Îndia iniciaria a política de ação afirmativa mais sistemática já realizada. Segundo Piketty: "De modo geral, a Constituição de 1950 começa abolindo todos os privilégios de casta e suprimindo toda e qualquer referência a religião" (p. 318). As políticas implementadas teriam reduzido significativamente a desigualdade na Índia entre os anos de 1950 e 20I0, com resultado superior ao da redução de desigualdades entre brancos e negros nos Estados Unidos e na África do Sul.

Uma das discussões mais interessantes do livro está no capítulo 9, "Sociedades ternárias e colonialismo: trajetórias euro-asiáticas". Aqui Piketty mostra como a dominação militar europeia se sustentou no desenvolvimento de uma capacidade fiscal e de administração dos Estados nacionais até então desconhecida. Importante o leitor atentar para esta passagem: a determinação dos países europeus de aumentar sua carga tributária não foi seguida pelos Estados otomano e chinês. Isso permitiu que os Estados europeus criassem uma capacidade militar superior e, com isso, dominassem tanto o Império Otomano quanto o Império Chinês. A França e a Inglaterra observaram suas 
dívidas públicas aumentarem fortemente. Situação distante das tão badaladas recomendações orçamentárias de Adam Smith no livro A riqueza das nações (p. 340).

Na terceira parte, "A grande transformação do século XX", Piketty analisa a transformação da estrutura da desigualdade. Ele afirma que, "entre I9I4 e I945, a estrutura das desigualdades mundiais, tanto no interior dos países quanto em nível internacional, ocorreu a mais rápida e mais profunda transformação jamais observada na história dos regimes desigualitários" (p. 373-374). Nesse período assistiu-se à queda das sociedades de proprietários, principalmente em razão da emergência do socialismo. Uma série de expropriações e nacionalizações foram realizadas em confronto com os detentores de riqueza.

Assim, na Rússia, investimentos estrangeiros, principalmente franceses, foram expropriados sem compensação financeira. Antes da Primeira Guerra Mundial, a aliança entre o Império Czarista e a República Francesa levou diversos empresários franceses a investir na Rússia. Após a tomada de poder pelos bolcheviques em I9I7, esses investimentos foram simplesmente cancelados pelos revolucionários, com o argumento de que aquele afluxo de capitais permitiu a prorrogação da ditadura czarista. Em 1956, a nacionalização do Canal de Suez levou à expropriação de acionistas britânicos e franceses que recebiam lucros e dividendos desde a inauguração do canal, em I869. Essas expropriações, afirma Piketty, ilustrariam perfeitamente "a virada político-ideológica do mundo durante a primeira metade do século XX" (p. 389) e a escalada de uma concepção mais social da propriedade, que levou a uma redução considerável das desigualdades econômicas.

Além do medo da Revolução Bolchevique, havia mais dois fatores objetivos: a terrível situação financeira de países como a França e o sangue derramado das classes populares na Primeira Guerra forçaram os ricos a dar sua parcela de contribuição para a melhoria das condições sociais. Desse modo, o imposto progressivo, com alíquota de 50\%, foi aprovado em I920 na França, sendo que antes a alíquota máxima era de somente $2 \%$. Além disso, a ideologia dominante nos Estados Unidos e no Reino Unido, que emergiu no pós-Segunda Guerra, compreendia que as "instituições eleitorais" deveriam ser complementadas por "instituições fiscais sólidas" que pudessem evitar que a democracia fosse capturada pelos "interesses financeiros e oligárquicos", e daí a necessidade de impostos fortemente progressivos (p. 405). É curioso como, em I9I9, Irving Fisher, economista neoclássico e presidente da American Economic Association, afirmava que a concentração de renda estaria próxima de se transformar no pior problema dos Estados Unidos, ameaçando os fundamentos da sociedade. Assim, ao se observar a trajetória da Europa e dos Estados Unidos ao longo do século XX, fica evidente que o aumento da capacidade tributária do Estado, além de não impedir o crescimento econômico, contribuiu para o desenvolvimento mais igualitário dessas sociedades.

Isso posto, Piketty busca compreender o fracasso das sociedades social-democratas a partir dos anos I980-I990. O autor questiona o porquê de as sociedades 
social-democratas não conseguirem lidar com o aumento da desigualdade após sua era de ouro, entre 1950-1980, quando desenvolveram práticas políticas e instituições que promoveram um ajuste social, da propriedade privada e do capitalismo, construído em vários países europeus e não europeus. A social-democracia é entendida de forma ampla, fazendo-se referência ao New Deal do governo Roosevelt nos Estados Unidos, à experiência do Partido Trabalhista na Inglaterra no pós-Segunda Guerra e, em particular, à experiência alemã de participação nas empresas — da qual Piketty é entusiasta - em que representantes dos trabalhadores são membros dos conselhos de administração.

De acordo com Piketty, os Estados Unidos tinham de longe o mais alto salário mínimo do mundo entre os anos I950 e I960. Em 20I9, porém, o poder de compra do salário mínimo perdera $30 \%$ em relação a meados do século anterior. Situação estranha para um país em paz e com crescimento econômico, mas que "demonstra a amplitude das mudanças político-ideológicas que marcaram os Estados Unidos desde os anos 1970-1980" (p. 468). Do mesmo modo, após um período de elevadas tarifas sobre as altíssimas rendas entre 1930 e 1980 , em torno de 70\% e 90\% nos Estados Unidos e Reino Unido, houve uma queda substancial dessas alíquotas a partir dos anos I980. O aumento da desigualdade também estaria relacionado com a ampliação dos investimentos privados em educação. Piketty afirma que nas universidades estadunidenses o processo de admissão é pouco transparente, e as famílias mais ricas, por meio de contribuições financeiras, conseguem obter a admissão dos seus filhos nas universidades mais prestigiadas. Isso provocaria uma forte desigualdade no acesso à educação nos Estados Unidos. A situação de dificuldade de acesso dos trabalhadores de baixa renda à educação não seria diferente na Europa, segundo o autor. A redução das alíquotas de impostos das maiores rendas, além da piora do acesso dos pobres à universidade, demonstraria que ocorreu uma política deliberada para concentrar renda.

Em outro ponto importante, Piketty adverte que a partir de 1980 , sob a influência estadunidense e europeia, a liberalização dos fluxos de capitais e a abertura comercial seriam realizadas em escala mundial, sem qualquer objetivo fiscal e social. Estávamos entrando na era em que o Estado-nação passava a ser cada vez mais questionado pela "revolução conservadora" anglo-saxã financiada por lobbies financeiros.

Piketty mostra o desastre que a "revolução conservadora" causou na Rússia em termos de política tributária após o fim da União Soviética. A ideia de imposto progressivo foi simplesmente abolida, além de se iniciar uma enorme evasão tributária. O resultado foi que um país que conseguiu reduzir a desigualdade a um dos níveis mais baixos da história se tornou um dos países mais "desigualitários" do mundo, líder mundial de bilionários em várias categorias, segundo as classificações da revista Forbes.

Outra questão levantada por Piketty refere-se ao empobrecimento das estatísticas públicas relacionadas à desigualdade justamente na chamada "era da informação". Ele atribui essa falta de transparência à ideologia "neoproprietarista" e à sua 
recusa em abrir a "caixa de Pandora" dos direitos de propriedade e de distribuição desta, impedindo assim a criação de um projeto redistributivo ousado.

A atual ideologia "neoproprietarista", mais complexa do que aquela do século XIX, se baseia num discurso meritocrático que exalta os vencedores enquanto rotula os perdedores do sistema econômico. Essa responsabilização dos mais pobres pela sua própria pobreza seria uma das principais características do sistema "desigualitário" atual. Ao mesmo tempo, vem ocorrendo a sacralização dos bilionários como empreendedores geniais e, por isso, merecedores de toda a riqueza que acumularam. Ainda segundo Piketty, a legitimação dos bilionários também se apresenta por meio da filantropia. Isso seria uma ilusão, já que esses que realizam a filantropia são os mesmos que se beneficiam das vantagens fiscais. Não por coincidência, o discurso filantrópico estaria atrelado à ideologia anti-Estado.

Na quarta parte da obra, "Repensar as dimensões do conflito político", Piketty discute os conflitos político-ideológicos quanto à justiça social, que se manifestam de diversas formas. Ele destaca os processos eleitorais e como o eleitor tem se posicionado entre a esquerda e a direita em dois períodos distintos: I950-I980 e 1990-2020. O tema é relevante porque, tomando como base o Reino Unido, França e Estados Unidos, Piketty mostra que a participação eleitoral se reduz conforme a desigualdade social aumenta. Detalhe importante refere-se à análise eleitoral nas diferentes profissões. Diz o autor: "Entre as categorias com menor grau de instrução que votavam em grande número nos partidos de esquerda nos anos I950-I960 e que, em grande parte, deixaram de votar nesses partidos nos anos 1990-2020, encontramos sobretudo os trabalhadores do setor industrial" (p. 65I). Piketty afirma que essa derrocada do voto operário nos partidos de esquerda (comunistas, social-democratas etc.) seria generalizada nos países ocidentais em razão da percepção entre os trabalhadores de que não se veriam mais representados por esses partidos em um contexto de redução do emprego industrial e da globalização. As categorias com menor tempo de estudo teriam passado a se sentir pouco representadas pelos tradicionais partidos de esquerda. Entre as categorias com maior grau de instrução que mantiveram seu voto na esquerda ou o transferiram para esse campo estão os professores e os funcionários públicos, além dos trabalhadores ligados às atividades da saúde e cultura.

A partir dessa constatação, Piketty lança o termo esquerda brâmane para compreender o contexto francês: a esquerda que deixou de ser o partido dos trabalhadores para se tornar o partido dos diplomados. Isso seria compreensível na visão do autor, já que os partidos de esquerda frisavam a promoção social pela educação, e esses eleitores com maior grau de instrução se sentiriam gratos, portanto. O problema é que esses partidos se afastaram progressivamente das massas populares, passando a nutrir a meritocracia como questão essencial à ascensão social. Além disso, Piketty afirma que o "regime educacional francês parece particularmente desigual e hipócrita" (p. 656), já que os gastos em educação voltados às camadas sociais menos favorecidas teriam sido inferiores aos destinados ao restante da população. Assim, enquanto 


\section{O livro apresenta um conjunto de dados estatísticos fundamentais para quem quer conhecer o problema da desigualdade no mundo}

a direita mercantilista acreditaria no mérito dos negócios, a esquerda brâmane insistiria no mérito escolar. Essa mesma estrutura pode ser encontrada nos Estados Unidos, no Reino Unido e em outros países do Ocidente, como Alemanha, Noruega e Suécia, conforme Piketty tentará demonstrar no capítulo I5. A explicação para a circunstância de que os mais humildes deixaram de confiar nos partidos de esquerda seria a falta de renovação dos programas desses partidos, impossibilitando sua adaptação aos "desafios surgidos na última metade do século", como a expansão educacional e a "globalização econômica" (p. 743).

Todavia, Piketty é otimista. A fase iniciada no começo da década de 1980 com Margaret Thatcher e Ronald Reagan estaria perto de terminar, em razão dos excessos da desregulamentação econômica consubstanciada na crise financeira de 2008 e no aumento vertiginoso da desigualdade social. Plataformas políticas centradas na defesa do status quo não deverão triunfar por muito tempo. Logo, o debate político será cada vez mais reorientado, segundo o autor.

O Brasil, um caso reconhecido de vergonhosa desigualdade de renda, também tem espaço na obra. Piketty analisa a trajetória do Partido dos Trabalhadores (PT) e conclui que o partido teve uma trajetória diferente dos partidos de esquerda ocidentais: inicialmente sua composição dos votos se concentrava nos eleitores com maior grau de instrução e renda um pouco mais elevada que a média do país. A partir de 2003, após a ascensão de Lula ao poder, o eleitorado petista passou a se concentrar mais entre os eleitores com menor grau de instrução e renda mais baixa. Essa mudança seria coerente com as políticas de redução da pobreza - como o programa Bolsa Família e a elevação do salário mínimo — adotadas por sucessivos governos do PT.

De forma elucidativa, Piketty aponta o insucesso dos governos petistas em relação à luta contra a desigualdade de renda. As rendas mais baixas foram beneficiadas, porém isso ocorreu em detrimento dos grupos sociais compreendidos entre os 50\% mais pobres e os I0\% mais ricos, a chamada classe média. Os IO\% mais ricos mantiveram sua posição e o I\% mais rico aumentou sua parcela na renda total. A razão desse resultado paradoxal teria sido a falta de uma reforma tributária que enfrentasse a regressividade estrutural do sistema tributário brasileiro. 
No último capítulo, Piketty apresenta uma proposta para o que ele denomina "socialismo participativo para o século XXI". Piketty acredita "que é possível erradicar o sistema capitalista atual e traçar os contornos de um novo socialismo participativo para o século XXI" (p. 820). Sobre as características do "socialismo participativo", ele lança um conjunto de proposições, como o compartilhamento do direito de voto nas empresas e o imposto progressivo sobre a renda e sobre a propriedade e circulação do capital. O imposto progressivo deveria ser a principal forma de financiamento do Estado de bem-estar social. No plano político o socialismo participativo contemplaria novas formas de representação de justiça e democracia, por via das quais o poder financeiro pudesse ser bastante reduzido em favor das representações populares.

O livro apresenta um conjunto de dados estatísticos fundamentais para quem quer conhecer o problema da desigualdade no mundo. Como destaca Piketty, o aumento da desigualdade nas últimas décadas não é natural, mas sim construído, como demonstra o exemplo da redução das alíquotas de imposto de renda dos ricos e a supressão do limite máximo do valor das doações privadas para as campanhas eleitorais nos Estados Unidos, proporcionando uma influência desmensurada do grande capital no processo eleitoral. É muito importante salientar a relevância que a Revolução Russa e a constituição do bloco socialista após a Segunda Guerra tiveram nas políticas distributivas em grande parte do mundo, e como tais políticas foram desconstruídas exatamente após a derrota das primeiras experiências socialistas. Agora, a luta por políticas inclusivas e igualitárias ganha força em diversos países. É terrível constatar que neste momento o Brasil está aplicando uma política neoliberal radical "desigualitária” cada vez mais questionada no Ocidente.

No entanto, Piketty resvala no utopismo quando propõe políticas de distribuição de renda e riqueza em nome de um socialismo igualitário que, na prática, seria implementado por decretos.

De todo modo, o livro é uma contribuição importante para o problema da distribuição de renda, que, no caso do Brasil, é uma pauta urgente para um novo governo que deverá emergir dos escombros deixados pelo neofascismo.

* Professor associado II e docente do Programa de Pós-Graduação em Economia Regional e Desenvolvimento (PPGER) da Universidade Federal Rural do Rio de Janeiro (UFRRJ). Doutor em Economia pela Universidade Federal Fluminense (UFF). Membro do Conselho Federal de Economia (Cofecon) e do Conselho Regional de Economia do Rio de Janeiro (Corecon-RJ). Membro do grupo de pesquisa Padrões Históricos do Desenvolvimento Econômico da América do Sul e do Laboratório Interdisciplinar de Estudos em Relações Internacionais. E-mail: mapefern@gmail.com

Texto recebido em 21 de novembro de 2021; aprovado em 22 de novembro de 2021. 